\title{
Does asymptomatic carriage of FV Leiden and Fll prothrombin mutations in heterozygous configuration pose an increased risk of thrombembolic complications in the course of pregnancy, labor and puerperium?
}

\author{
Blanka Vavrinkova ${ }^{a}$, Tomas Binder ${ }^{\mathrm{a}}$, Ivana Hadacovab ${ }^{\mathrm{b}}$ Ingrid Hrachovinovac, Peter Salaj', Martin Hruda ${ }^{\mathrm{a}}$
}

\begin{abstract}
Objective. To evaluate the course of pregnancy and puerperium in asymptomatic carriers of FV Leiden and FII prothrombin mutation in heterozygous configuration in terms of risk of thrombembolic disease (TED) and late pregnancy complications. To evaluate whether global prophylactic LMWH administration during pregnancy benefits these women. Methods. We monitored the incidence of thrombembolic events and severe late pregnancy complications in 473 asymptomatic carriers of FV Leiden and Fll prothrombin mutation in heterozygous configuration. In 253 women, preventive LMWH application was introduced already during pregnancy. In 220 women, the application of LMWH was commenced as late as on the delivery day. In both groups application of LMWH continued during the puerperium.

Results. The incidence of TED in the whole group of carriers of thrombophylic mutations accounted for $0.19 \%$. The incidence of severe late pregnancy complications was low - $2.5 \%$ compared with general population of pregnant women (6.4\%).

Conclusions. No direct causal relationship was established between asymptomatic carriage of Leiden and prothrombin mutation in heterozygous configuration and the occurrence of severe late pregnancy complications. There was no benefit from general LMWH prophylaxis started as early as pregnancy in these women and thus we consider it unnecessary.
\end{abstract}

Key words: FV Leiden mutation, Fll prothrombin mutation, LMWH prophylaxis, severe late pregnancy complications, abruption of placenta, HELLP syndrome, severe preeclampsia, stillbirth, IUGR

Received: January 3, 2012; Accepted with revision: July 4, 2012; Available online: October 31, 2012

http://dx.doi.org/10.5507/bp.2012.070

${ }^{a}$ Department of Obstetrics and Gynaecology, $2^{\text {nd }}$ Faculty of Medicine, Charles University in Prague and Teaching Hospital Motol, Prague, Czech Republic

${ }^{b}$ Department of Hematology, Teaching Hospital Motol, Prague

Institute of Hematology and Blood Transfusion, Prague

Corresponding author: Blanka Vavrinkova, e-mail: blanka@vavrinkova.cz

\section{INTRODUCTION}

Pregnancy of carriers of thrombophylic mutations (TM) is considered by many authors to be associated with a high risk in terms of development of both thrombembolic disease and severe late pregnancy complications. The factor V Leiden mutation results from a substitution of adenine for the normal guanine at the 1691 position of the factor $\mathrm{V}$ gene. As a result, factor $\mathrm{V}$ becomes resistant to cleavage by activated protein $\mathrm{C}$. Factor V Leiden mutation is rare in Asian and African populations and is higher in European population, with the highest frequency reported in the Eastern Mediterranean region. 20210 position of the protrombin gene enhances the function of prothrombin (factor II) and results in an increased risk of thrombosis. The prothrombin heterozygote mutation occurs in approximately $2 \%$ of the general population but appears to be less common in African Americans. The genes for factor V Leiden and prothrombin follow an autosomal dominant pattern of inheritance because the heterozygote is considered an increased risk for thrombosis.

The incidence of the Leiden mutation in Caucasian populations is estimated between $5-7 \%$ and of prothrom- bin mutation between $2-3 \%$ of individuals ${ }^{1}$.Global screening is not performed in any country, including the Czech Republic. Selective screening is recommended in individuals with a family history, history of thrombebolic events and quite recently also in women with habitual miscarriage, infertility as such or in women with severe late pregnancy complications ${ }^{1-4}$. As a result there are thousands of carriers of thrombophylic mutations who undergo an uneventful pregnancy every year that were not identified. In general, the biggest group comprises asymptomatic carriers of the Leiden and prothrombin mutation in heterozygous configuration. In more than a half of them, hematologists start prophylactic LMWH administration as early as in the course of pregnancy, as a rule between the $20^{\text {th }}$ and $30^{\text {th }}$ gestation week. The primary reason for such a step are hemocoagulation changes that however are physiological during pregnancy, including elevated serum levels of fibrinogen, FVIII, a positive D-dimer test and decrease of free protein S (Fig. 1).

The aim of our study was to find out whether carriage of these most frequent mutations in heterozygous configuration poses an increased risk of developing severe late pregnancy complications and if prophylactic LMWH 


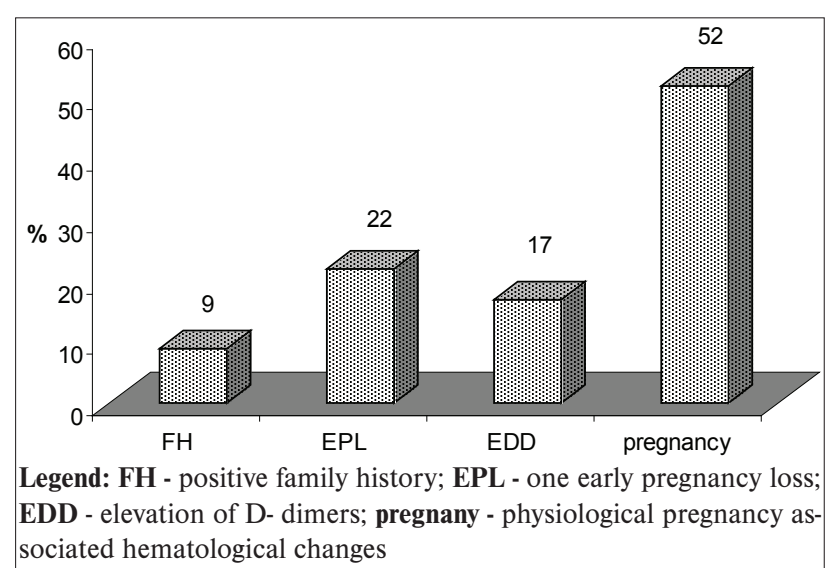

Fig. 1. The reasons for comencment LMWH prophylaxis during the course of pregnancy.

administration has some positive effect on the course of pregnancy.

\section{MATERIAL AND METHOD}

Perinatology Center of Department of Obstetrics and Gynecology of the Motol Teaching Hospital in Prague is a specialized unit that among other things concentrates on pregnant women with hematological disorders and diseases. Between June 2007 and June 2011 we carried out a prospective study of 473 pregnant asymptomatic carriers of the Leiden mutation (401) and prothrombin mutation (72) in heterozygous configuration. Genomic deoxyribonucleic acid was extracted from whole blood by high salt precipitation. Genotypes were determined by polymerase chain reaction followed by restriction enzyme digestion and gel electrophoresis.

A total of 253 women (group A) were referred to our Center for prenatal care with already commenced prophylactic LMWH application from hematological centers in Prague and the Central Bohemian region. The reasons for commencement of LMWH prophylaxis in these women are shown in Fig. 1. The most frequent reason was pregnancy as such and physiological hemocoagulation changes during pregnancy (47\%). In 220 women (group B) monitored from the beginning of their pregnancy in our Center, LMWH prophylaxis was started as late as on the day of onset of labor

Pregnant women with multiple pregnancy, women with 2 and more early pregnancy losses, women with the history of severe late pregnancy complications and chronically ill women were not enrolled in the study. In all the women included in the study, extension of prophylactic LMWH application over the whole period of puerperium was recommended. All signed the inform consent and the study design was approved by hospital Ethical Committee.

Both groups were followed up in terms of incidence of thromboembolic events and severe late pregnancy complications, such as IUGR below 5 percentile of national birth weight tables, abruption of placenta, HELLP syndrome, severe form of preeclampsia and stillbirth. We evaluated the birth weight a head circumference of the newborns.
A total of 13353 labors were performed during the monitored period in the Motol Teaching Hospital in Prague. If we eliminate multiple pregnancies and pregnancies of women with symptomatic carriage of any of TM or with proven carriage of more mutations or carriage of a mutation in homozygous configuration, then from the viewpoint of incidence of late pregnancy complications we compare 12431 single pregnancies in women in which carriage of thrombophylic mutation was not examined or proved.

\section{RESULTS}

In the cohort of 253 women (group A) with prophylactic LMWH application during pregnancy, the mean gestational age at the time of delivery was $38+5$, the mean of newborns birth weight was $3450 \mathrm{~g}$, the mean head circumference was $34 \mathrm{~cm}$. We recorded 2 cases of severe IUGR $(0.79 \%), 1$ case of placenta abruption $(0.39 \%), 2$ cases of developed HELLP syndrome $(0.79 \%), 2$ cases of a more severe form of preeclampsia $(0.79 \%)$ and one case of stillbirth $(0.39 \%)$. In one woman we diagnosed a deep venous thrombosis of the left calf on $3^{\text {rd }}$ day after delivery $(0.39 \%)$. Late pregnancy complications and mother's thrombembolic disease (TED) endangered $3.56 \%$ of pregnancies.

In the cohort of 220 women (group B) without prophylactic LMWH application during pregnancy, the mean gestational age at the time of delivery was $38+3$, the mean birth weight of newborns was $3365 \mathrm{~g}$, the mean head circumference was $34.5 \mathrm{~cm}$. We recorded one case of severe IUGR $(0.45 \%)$ and no case of placenta abruption, HELLP syndrome or stillbirth. We recorded only 2 cases of a more severe form of preeclampsia $(0.9 \%)$. The incidence of severe late pregnancy complications was $1.4 \%$ in this group.

In total, we recorded during the monitored period in all asymptomatic carriers of any of the monitored TM in heterozygous configuration the incidence of late pregnancy complications in $2.5 \%$ of cases.

In the selected group of 12431 single pregnancies without proven carriage of thrombophylic mutation, the mean gestational age was $38+3$, the mean birth weight of newborns was $3412 \mathrm{~g}$, the mean head circumference was 34.45 $\mathrm{cm}$. We retrospectively recorded 57 cases of severe IUGR $(0.46 \%), 83$ cases of placenta abruption $(0.67 \%), 78$ cases of HELLP syndrome $(0.63 \%)$ and 525 cases of a severe form of preeclampsia (4.22\%). Stillbirth was recorded in 39 cases $(0.31 \%)$. During pregnancy and puerperium we recorded 16 cases of deep vein thrombosis and 2 cases of pulmonary embolism $(0.16 \%)$. The total incidence of severe late pregnancy complications and TED in this group was $6.4 \%$.

Table 1 shows comparison of the monitored indicators between carriers of thrombophylic mutations with prophylactic LMWH application started already during pregnancy and TM carriers with LMWH prophylaxis commenced on the onset of labor. 
Table 1. Comparison of monitored perinatological parametres and severe late pregnancy complications in asymptomatic carriers of TM FV Leiden or FII prothrombin in heterozygous configuration with ( A) and without (B) prophylaxís LMWH during pregnancy.

\begin{tabular}{|c|c|c|c|c|c|c|c|c|c|}
\hline & $\begin{array}{c}\text { Gest. } \\
\text { week } \\
\text { (mean) }\end{array}$ & $\begin{array}{l}\text { Birth } \\
\text { weight } \\
(\mathrm{g}) \\
\text { (mean) }\end{array}$ & $\begin{array}{l}\text { Head } \\
\text { circum- } \\
\text { ference } \\
(\mathrm{cm}) \\
\text { (mean) }\end{array}$ & $\begin{array}{c}\text { IUGR } \\
<5 \text { percentil }\end{array}$ & $\begin{array}{c}\text { Abruption } \\
\text { of } \\
\text { placenta }\end{array}$ & $\begin{array}{l}\text { HELLP } \\
\text { sy, }\end{array}$ & Preeclampsia & Stillbirth & TED \\
\hline $\begin{array}{c}\text { A } \\
\mathrm{n}-253\end{array}$ & $\begin{array}{c}38+5 \\
\text { SD } 3+5\end{array}$ & $\begin{array}{c}3450 \\
\text { SD } 422\end{array}$ & $\begin{array}{c}34 \\
\text { SD } 1,29\end{array}$ & 2 & 1 & 2 & 2 & 1 & 1 \\
\hline $\begin{array}{c}\text { B } \\
n-220\end{array}$ & $\begin{array}{c}38+3 \\
\text { SD } 3+6\end{array}$ & $\begin{array}{c}3365 \\
\text { SD } 387\end{array}$ & $\begin{array}{c}34,5 \\
\text { SD } 1,19\end{array}$ & 1 & 0 & 0 & 2 & 0 & 0 \\
\hline $\begin{array}{c}P \\
\text { value }\end{array}$ & 0.254 & N.S. & N.S. & N.S. & N.S. & N.S. & N.S. & N.S. & N.S. \\
\hline
\end{tabular}

Legend: TM - thrombophylic mutation; TED - thrombemboli disease; SD - standard deviation

Table 2. Comparison of monitored perinatological parametres and severe late pregnancy complications in asymptomatic carriers of TM FV Leiden or FII prothrombin in heterozygous configuration and women with single pregnancy with negative or unknown TM status.

\begin{tabular}{|c|c|c|c|c|c|c|c|c|c|}
\hline & $\begin{array}{c}\text { Gest. } \\
\text { week } \\
\text { (mean) }\end{array}$ & $\begin{array}{l}\text { Birth } \\
\text { weight } \\
(\mathrm{g}) \\
\text { (mean) }\end{array}$ & $\begin{array}{l}\text { Head } \\
\text { circum- } \\
\text { ference } \\
(\mathrm{cm}) \\
(\text { mean })\end{array}$ & $\begin{array}{c}\text { IUGR } \\
<5 \text { percentil }\end{array}$ & $\begin{array}{l}\text { Abruption } \\
\text { of } \\
\text { placenta }\end{array}$ & $\begin{array}{l}\text { HELLP } \\
\text { sy, }\end{array}$ & Preeclampsia & Stillbirth & TED \\
\hline $\begin{array}{c}\text { TM } \\
\text { n-473 }\end{array}$ & $\begin{array}{c}38+5 \\
\text { SD } 3+6\end{array}$ & $\begin{array}{c}3395 \\
\text { SD } 401\end{array}$ & $\begin{array}{c}34,25 \\
\text { SD } 1,3\end{array}$ & 3 & 1 & 2 & 4 & 1 & 1 \\
\hline $\begin{array}{c}\text { TM- } \\
\text { n- } 12431\end{array}$ & $\begin{array}{c}38+3 \\
\text { SD } 3+5\end{array}$ & $\begin{array}{c}3412 \\
\text { SD } 463\end{array}$ & $\begin{array}{c}34,45 \\
\text { SD } 1,46\end{array}$ & 57 & 83 & 78 & 525 & 39 & 16 \\
\hline$P$ value & N.S. & N.S. & N.S. & 0.326 & 0.0567 & N.S. & 0.00321 & N.S. & N.S. \\
\hline
\end{tabular}

Legend: TM - thrombophylic mutation; TED - thrombemboli disease; SD - standard deviation

No statistically significant differences were found in any of the monitored indicators.

Table 2 shows comparison of monitored indicators of all asymptomatic carriers of FV Leiden and F II prothrombin mutations in heterozygous configuration $(\mathrm{TM}+)$ with a selected group of single pregnancies with eliminated or unidentified TM carriage (TM - or ?).

A statistically significant difference to the disadvantage of the group with eliminated or unidentified carriage of TM was recorded in case of preeclampsia, while in other monitored indicators no statistically significant differences were found.

\section{DISCUSSION}

Despite all efforts, thrombembolic disease (TED) is still one of the most frequent causes of life-threatening complications in pregnant women ${ }^{5,6}$. Even with all the preventive measures taken, it cannot be stated that the absolute number of thromboses during pregnancy has significantly decreased, but what has definitely decreased is the number of fatal cases resulting in the death of the pregnant woman ${ }^{7}$. What is the role of prevention and what is the contribution of early diagnosis and treatment in this respect is hard to express.

Pregnancy by itself presents a thrombophylic situation. Quite a large amount of financial means is being spent on TED prevention during pregnancy, labor and puerperium, that is today ensured exclusively by low-molecularweight heparins. Historically, the indications concerned primarily prevention during onset of labor. However, in the last 20 years, increased attention has been devoted to carriers of any of thrombophylic conditions, the carriers of thrombophylic mutations in particular, already during the pregnancy to prevent not only TED but also the severe late pregnancy complications. Peripartal prevention is the sole responsibility of obstetricians, while TED prevention is treated in the absolute majority of cases by hematologists. There are not many specialists all over the world who would deal purely with thrombosis and would be at the same time familiar with the respective obstetrics issues and of course there are only few obstetricians who deal with issues of hemocoagulation. For this reason, the approach and the measures taken in individual institutions may differ quite significantly, even despite recommendations of $7^{\text {th }}$ ACCP Conference ${ }^{3}$ that dealt with the issues of thrombembolic complications in pregnancy. 
In general, prevention should be targeted and efficient. The question is whether this is true in prevention of late pregnancy complication. This theme remains controversial. There is no clear evidence of a direct relationship between carriage of inherited TM and higher risk of developing late pregnancy complications ${ }^{8}$, but in clinical practice the fact of carriage of any of the thrombophylic mutations in combination with pregnancy is rationale for prophylactic LMWH use during pregnancy. This preventive use of LMWH replaces the individual approach in observation of these carriers during pregnancy in terms of hemocoagulation changes, clinical status or emergence of additional transient risk factors. This approach we consider wrong. If we ignore the financial costs, we cannot ignore the discomfort of the patient and potential risks of this treatment ${ }^{9,10,11}$.

\section{CONCLUSION}

Pregnancy in asymptomatic carriers of FV Leiden and FII prothrombin mutations in heterozygous configuration does not differ from pregnancy in "healthy women". They are not associated with a markedly higher risk of development of severe late pregnancy complications such as IUGR, placenta abruption, HELLP syndrome, preeclampsia or stillbirth ${ }^{10}$. Neither have we proven a higher risk of the development of thrombembolic events during the course of pregnancy. We found no proof that these women would profit from preventive application of LMWH commenced during pregnancy and as a result we consider it unnecessary ${ }^{1,3}$.

TED prophylaxis by LMWH use during onset of labor and extended over the whole period of puerperium we consider indicated. Upon discharge from the hospital it is necessary to inform the women properly and emphasize the necessity of continuation of LMWH prophylaxis in the course of puerperium ${ }^{3,9,12}$.

\section{STATISTICAL ANALYSIS}

Individual groups were compared using the KruskalWallis ANOVA test. Correlation of dichotomic variables was evaluated by means of longlinear models. Calculations were done by means of NCSS 2002 statistical software
(Number Cruncher Statistical Systems, Kaysville, UT, USA).

\section{CONFLICT OF INTEREST STATEMENT}

The authors state that there are no conflicts of interest regarding the publication of this article.

\section{REFERENCES}

1. Bates SM, Greer IA, Hirsh J, Gingsberg JS. Use of antithrombotic Agents During Pregnancy Chest 2004;126(S3):627-44.

2. Greer IA. Prevention and management of venous thrombembolism in pregnancy. Clin Chest Med 2003;24:123-37.

3. Geerts WH, Berquist D, Pineo GF, Heit JA, Samama CM, Lassen MR, Colwell CW; American College of Chest Physicians. Prevention of venous thrombembolism: American Chest Physicians EvidenceBased Clinical Practice Guidelines ( $8^{\text {th }}$ Edition) Chest, 2008;133:6 suppl:381-453.

4. Rodger MA, Carrier M, Keely E, Karovitch A, Nimrod C, Walker M, Wells PS. The management of thrombophilia during pregnancy: a Canadian survey. J Obstet Gynaecol Can 2002;24(12):946-52.

5. Martinelli I, Battaglioli T, De Stefano V, Tormene D, Valdrè L, Grandone E, Tosetto A, Mannucci PM; GIT (Gruppo Italiano Trombofilia). The risk of first venousus thrombembolism during pregnancy and puerperium in double heterozygotes for factor $V$ Leiden and prothrombin G20210A. J Thromb Haemost 2008;6(3):494-8.

6. Samama MM, Rached RA, Conard J, Horellou MH, Elalamy J. Pregnancy - associated venous thrombosis in women with hereditary heterozygous factor Leiden and/or factor II gene mutations. Bull Acad Natl Med 2004;188(8):1377-93.

7. O'Connor DJ, Scher LA, Gargiulo NJ 3rd, Jang J, Suggs WD, Lipsitz EC. Incidence and Characteristics of Venous Thrombembolic Disease During Pregnancy and the Postnatal Period: A Contemporary Series. Ann Vasc Surg 2011;25(1):9-14.

8. Prochazka M, Lubusky M, Zelina P, Kudela M, Lindquist PG: Frequency in selected trombophilias in women with placental abruption. Austr and New Zeland J of Obst and Gyn 2007;47,297-301.

9. Rodger MA. Anticoagulant prophylaxis for placenta mediated pregnancy complications. Thromb Research 2011;127Suppl.3:76-80

10. Papaian LP, Kobilianskaia Va, Sheldina AM, Baranovskaia SS, Sirotkina OV, Kargin VD, Saltykova NB, Beliazo OE, Golovina OG, Papaian KA, Tarkovskaia LR. Changes in hemostasis system in patients with hereditary thrombophilia caused by mutation of blood coagulation factor V (factor V Leiden). Ter Arkh 2001;73(7):47-51.

11. Middeldorp S, Meinardi JR, Koopman MM, van Pampus EC, Hamulyák K, van Der Meer J, Prins MH, Büller HR. A prospective study of asymptomatic carriers of the factor $V$ Leiden mutation to dermine the incidence of venous thrombembolism. Ann Intern Med 2001;135(5):322-7.

12. Bates SM, Greer IA, Pubinger I, Sofaer S, Hirsh J. Venous Thrombembolism, Thrombophilia, Antithormbotic Therapy and Pregnancy. Chest, 2008;133:6 suppl. 844-86. 